\title{
Farmacêutico: profissional de saúde e cidadão
}

\author{
The pharmacist: health professional and citizen
}

Suely Rozenfeld ${ }^{1}$

\footnotetext{
${ }^{1}$ Escola N acional de Saúde Pública, Fundação Oswaldo Cruz. Rua Leopoldo Bulhões 1480, M anguinhos. 21041-210 Rio de Janeiro Brasil.

rozenfel@ensp.fiocruz.br
}

\begin{abstract}
This text was presented at the $V$ Congress on Pharmacy Care/Riopharma with the intent to approach some aspects important for discussing the role of the pharmacist as health professional and citizen capable of acting in society. To this purpose we decided to recall some of the cornerstones of the Brazilian health reform; the pressure of the industry on health professionals and regulatory agencies; the inequity in the distribution of medicaments among the different social classes. Some of the changes proposed in this paper are: to widen the rolethe pharmacist plays in pharmacotherapy; to prohibit drug advertising; a global and independent evaluation of the national regulatory agency; inclusion of information about medicament consumption during hospitalizations in the national databases.

Key words Pharmaceutical Care, Government regulation, $\mathrm{N}$ ational Policy of Pharmaceutical Assistance, Pharmacists
\end{abstract}

Resumo 0 texto foi apresentado no $\mathrm{V}$ Congresso de Assistência Farmacêutica/Riopharma, com 0 objetivo de abordar aspectos importantes para a reflexão da condição do farmacêutico como profissional e como cidadão capaz de atuar em sociedade. Para tanto, o caminho selecionado foi a rememoração de alguns fundamentos que estruturam a reforma sanitária no Brasil; a pressão dos fabricantessobreos profissionais desaúdeeasagências reguladoras; a desigualdade na distribuição dos medicamentos entre os diferentes estratos sociais. Entre as propostas de mudança apontadas estão: a ampliação do papel do farmacêutico na atenção farmacoterapêutica; a proibição da propaganda demedicamentos; a avaliação global eindependente da agência de regulação nacional; ea inclusão nas bases de dados nacionais de informações sobre medicamentos consumidos durante as hospitalizações.

Palavras-chave Assistência farmacêutica, Regulamentação governamental, Política Nacional de Assistência Farmacêutica, Farmacêuticos 


\section{Panoramageral}

Estamos vivendo tempos difíceis.

Oscenários nacional einternacional se transformaram com muita rapidez, nas últimas duas décadas. $M$ as, infelizmente, não parece ter sido para melhor. As transformações se operaram a partir da implantação das mudanças neoli berais, características de um modelo selvagem de economia capitalista. E, também, das dificuldades de alguns países construírem alternativas capazes de se generalizar com igualdade social e com liberdadepolítica.

Temos sido atores e platéia de um espetáculo no qual predomina o mercado, que avassala 0 conjunto da sociedade e se sobrepõe a todas as outras dimensões da vida humana. Sucessos evitórias, pessoais ou coletivos, são medidos pela impiedosa métrica do dinheiro. Importa ter e não ser. Importa parecer ter e não verdadeiramente ser.

Nós, que trabalhamos em saúde pública há muito tempo, temos sentido essas mudanças no cotidiano.

Nas décadas de 1970 e 1980, acreditávamos na capacidade de os governos oferecerem, com eqüidade, saúde e educação de boa qualidade. Acreditávamos no papel articulador dos organismos internacionais. Acreditávamos nas políticas de bem-estar social e de direitos civis. Acreditávamos na organização das pessoas em torno a interesses legítimos, como forma ideal de fazer valer os direitos dos cidadãos.

Essas crenças produziram, entre outras ações igualmente positivas, a consigna da OM S Saúde para todos no ano 2000 e as mudanças na Constituição Federal do nosso país, que preconizavam Saúde como direito de todos edever do Estado e resultaram na criação do Sistema Ú nico de Saúde, universal e gratuito.

M as, a partir da década de 1990, o panorama de transformou. A privatização invadiu o Estado e a desigual dade cresceu.

No campo institucional, sabe-se que o Sistema Ú nico de Saúde garante universalidade e integralidade. M as ele tem sido alvejado por pressões para privatização. Os que apostam no fracasso do Sistema apregoam, aos quatro ventos, que ele não funciona por ser estatal. Na verdade, ele funciona mal por ser pouco estatal e muito impregnado pela lógica mercantil, em especial para medicamentos e equipamentos. $\mathrm{Na}$ outra ponta, há os planos de saúde, campeões de queixas nos órgãos de defesa do consumidor. $\mathrm{Na}$ Constituição de 1988, eles foram chamados "assistência complementar". Hoje, envolvem quase um terço da população brasileira e se transformaram em assistência principal para os que podem pagar.

Denúncias de corrupção põem a nu as perigosas ligações entre as elites econômicas e as esferas republicanas, eproduzem um clima de desconfiança de todos contra todos.

No campo dos profissionais de saúde, operaram-se transformações ideológicas preocupantes. Setores antes comprometidos com bandeiras progressistas foram cooptados nos balcões de negócio do poder executivo. Eles acenam com infinitas e diversificadas possibilidades de financiamento de projetos, ajustados aos moldes privados. E os profissionais, ainda quando bem intencionados, ficam reféns da lógica de produzir sem produzir qualquer impacto. Uma quantidade interminável de cursos, seminários, congressos, reuniões, oficinas - inúmeras vezes redundantes e sem objetivos claros - substituem a idéia generosa de preparar recursos humanos para as transformações que a sociedade requer. Incontáveis publicações, softwares, filmes e vídeos, elaborados com competência técnica, adormecem em prateleiras, sem qualquer utilidade. $A$ energia despendida na sua preparação entorpece corações e mentes, e produz a confortável sensação de se estar fazendo alguma coisa útil. 0 resultado é o distanciamento crescente dos profissionais do seu alvo: prover saúde, sobretudo para a imensa parcela da população que não pode comprá-la.

"Organismosnão governamentais" saídos da luta contra a ditadura, das lutas sindicais, dos movimentos de mulheres, foram sendo substituídos por "indivíduos não governamentais" que, em nomede bandeiras populares elegítimas, captam dinheiro público para benefícios privados. Esse fenômeno se generalizou de tal forma que, recentemente, provocou a revolta pública do músico Zé Rodrix. Ao saber que haveria cobrança de ingressos, ele abandonou a direção de um espetáculo financiado com recursos da Lei Rouanet - que desonera do pagamento de impostos as empresas queapóiam manifestações culturais. Segundo ele, o dinheiro detodos, que paga a aventura artística de alguns, deveria voltar integralmente para o povo ${ }^{1}$.

Os indicadores econômicos, sobretudo os do mercado financeiro, mostram vitalidade. 0 lucro líquido declarado do Banco I taú, no primeiro semestre do ano de 2007, foi de 4 bilhões de reais, $36 \%$ superior ao do ano anterior. 0 banco já anunciou que, no segundo semestre de 2007, 0 lucro será ainda maior ${ }^{2}$. No setor farmacêutico, 
crescem as fusões entre as empresas e desativa-se a produção nacional. 0 nome dos ben eficiários dos lucros exorbitantes fica oculto no mercado de ações. E, como aponta M árcia Angell ${ }^{3}$, os executivos da indústria farmacêutica são pagos com ações da bolsa de valores. Portanto, são grandes interessados em valorizá-las a partir dos lucros obtidos com as vendas. Quando se torna público que um produto, até então considerado seguro, énocivo à saúde, as ações da empresa proprietária da marca despencam.

Já os indicadores sociais caminham a passos de tartaruga. A mortalidade infantil caiu de 53 para 29 óbitos por 1.000 nascidos vivos. M as, isso aconteceu entre 1990 e 2005, ou seja, num período de quinze anos ${ }^{4}$. N esse ritmo, para che gar às taxas de Cuba, hoje, talvez tenhamos que esperar até 0 ano 2025! 0 percentual da população brasileira na condição de extrema pobreza também caiu, de 9,5\% para 4,2\% . I sso aconteceu entre 1992 e 20055, ou seja, em treze anos. Nesse passo, não assistiremos à erradicação da pobreza absoluta antes de 2020. Os resultados minguados se devem à substituição dos grandes planos nacionais por propostas fragmentadas. A aceitação da idéia de que tudo é complexo, tudo é demorado, tudo é difícil, tem justificado a implantação de políticas focais, incompletas, descontínuas e de baixa resolutividade.

Os dados da última Pnad confirmam o efeito desse tipo de políticas sociais.

0 percentual de domicílios com esgoto sanitário adequado subiu de $70 \%$ para $71 \%$, entre 2005 e 2006, o que significa 1/3 dos lares sem 0 benefício. Quanto à ligação do esgoto doméstico à rede coletora, o quadro é ainda pior: cerca de metade dos domicílios não tem ligação com a rede de esgoto ${ }^{6}$. Ao examinar a situação do trabalho infantil, vê-se que a proporção de crianças, entre 5 e 17 anos de idade, que trabalham caiu menos de $1 \%$ entre 2005 e 20067 . Ainda que esse valor não fosse mera oscilação dos números, teríamos que lamentar que o combate ao emprego da mão-de-obra infantil deixa longe da escola, e sujeitos aos agravos do trabal ho precoce, 5 milhões dejovens.

Alguns poderiam alegar que, afinal de contas, as coisas estão melhorando, e que é preciso esperar para ver os benefícios estendidos a todos. A esses, respondemos que não se trata apenas de velocidadee detempo das mudanças. Trata-se de aceitar que seja operado um modelo de sociedade que tolera iniqüidades inaceitáveis. Bastaria uma única criança submetida ao trabaIho, ou um único lar sem ligação com a rede de esgoto, para que fossemos questionados como nação digna e soberana. 0 país que nega à imensa parcela dos seus cidadãos direitos e benefícios conquistados há mais de cem anos, e permite que uma minoria seja contemplada com as oportunidades e o conforto do terceiro milênio, precisa redefinir seu rumo.

\section{M edicamentos}

\section{As pressões dos fabricantes}

A modernidade tecnológica não vem sendo impulsionada por necessidades definidas por critérios epidemiológicos, mas pela pressão dos fabricantes, para vender muito erápido. Os danos produzidos por novidadesinsuficientementetestadas, ou por produtos nocivos, cobram seu preço em recursos materiais, já escassos, e em vidas humanas.

Entre as principais causas dos erros e danos associados às ações de assistência à saúde está a falta de independência dos médicos, e das autoridades sanitárias, em relação aos interesses da indústria.

A pressão dos fabricantes sobre os médicose pesquisadores semprefoi intensa. Ainda hoje, os brindes são moeda corrente para a compra das consciências. Estima-se que $83 \%$ dos médicos norte-americanos recebam presentes dos fabricantes de medicamentos e equipamentos, na forma de alimentos, bebidas e ingressos para eventos esportivos ou culturais ${ }^{8}$. Supõe-se que essas práticas sejam mais intensas em países como 0 nosso, com atuação tímida da vigilância sanitária. Elas geram um campo de influência do fabricante que nada tem de científico. Exemplo número 1 das conseqüências: as pesquisas patrocinadas pela indústria farmacêutica têm probabilidade maior de apresentar resultados favoráveis aos novos fármacos, comparados aos tradicionais, do que as pesquisas independentes ${ }^{9}$. Exemplo número 2: é comum pesquisas patrocinadas pelos fabricantes de medicamentos serem interrompidas antes do programado, sob a justificativa da revel ação de resultados benéficos. São estudos com resultados falaciosos, que costumam distorcer as conseqüências de longo prazo dos tratamentos, quando ocorrem efeitos adversos graves $^{10}$.

As pressões dos fabricantes não atingem apenas médicos e pesquisadores. Organismos internacionais não têm se destacado por ações independentes. Vou dar dois exemplos: o FDA ea OMS. 
Desde 1992, os Estados Unidos delegaram à indústria farmacêutica a função de pagar os salários dos cientistas do FDA que analisam os pedidos de registro de novos medicamentos. A agência, pressionada para fornecer registros em tempo menor, em vez de solicitar mais recursos federais para contratar pesquisadores, preferiu sustentar seus empregados com recursos dos fabricantes. Com isso, o "cliente" passou a ser a indústria farmacêutica e não a população norteamericana. A ação reguladora da agência, queno passado gozava de credibilidadeno mundo todo, se enfraqueceu. Uma das conseqüências: a FDA autorizou a continuação da venda do antiinflamatório rofecoxib (Vioxx $®$, da M erck) por mais cinco anos, mesmo após publicadas as provas de que a substância dobra o risco de os usuários apresentarem derrame e infarto do miocárdio. Além do aspecto sanitário, a medida resulta em gastos com compras de $\$ 2,5$ bilhões por ano, dos quais um bilhão é dinheiro público ${ }^{11}$.

Problemas de complacência com os interesses da indústria têm incidido, também, sobre a Organização M undial da Saúde. No inicio do ano, a sua diretora geral foi duramente criticada por pesquisadores e membros da organização M édicos Sem Fronteiras. Ela sugeriu que o governo da Tailândia deveria negociar, de forma "equilibrada", com as empresas farmacêuticas, o licenciamento compulsório para fabricação de gené ricos de anti-retrovirais e de trombolíticos!12

\section{0 acesso e 0 excesso}

Vivemos numa das sociedades mais desiguais do planeta. No consumo de medicamentos, as desigualdades também aparecem nos números: $15 \%$ a $20 \%$ da população não têm acesso a nenhum tipo de medicamento e cerca de $50 \%$ dos pacientes deixam de conseguir algum remédio que precisariam, por não o encontrar na rede pública de saúde. Para as camadas mais pobres da população, os gastos com medicamentos podem comprometer $90 \%$ dos gastos com saúde, que aparecem em quarto lugar entre os gastos familiares do brasileiro, atrás apenas de habitação, alimentação e transporte ${ }^{13}$.

Se o salário é curto para tratar as doenças comuns, com antibióticos, antiinflamatórios ou anti-hipertensivos, a situação émais grave quando se trata das doenças negligenciadas. A pesquisa com novos fármacos não atrai investimentos das grandes corporações farmacêuticas, a pretexto de os tratamentos serem pouco lucrativos. Uma das doen ças negligenciadas é a leishmanio- se visceral, cuja incidência vem aumentando nas regiões $\mathrm{N}$ orte, Centro-Oeste e Sudeste, principalmenteem M inas Gerais. $O$ tratamento éfeito a base deantimoniais injetáveis, usados no mundo todo há mais de setenta anos. M as ele é doloroso, muito tóxico e há resistência em alguns países. Uma das poucas alternativas terapêuticas é a anfotericina $B$, cujo preço do tratamento varia entre US $\$ 1.500$ a US $\$ 2.400$, muito além do alcance da maioria dos pacientes ${ }^{14}$.

Uma das formas de tornar o medicamento mais acessível seria com o licenciamento compulsório, conhecido por "quebra de patentes". É um recurso previsto na lei brasileira e permite que, em algumas situações, outros fabricantes possam comercializar produtos patenteados. Isso diminui os preços e possibilita o acesso de um maior número depessoas ${ }^{13}$. Entretanto, também nessa área vamos aos tropeços. Os preços negociados pelo Brasil para os anti-retrovirais ficaram até quatro vezes mais caros do que os preços praticados no mercado internacional. Além disso, as transações do governo com os fabricantes acabaram por paralisar o desenvolvimento da capacidade de o nosso país fabricar genéricos ${ }^{12}$ : a produção de fármacos anti-retrovirais não é expressiva nem sistemática.

Outra iniciativa recente para diminuir preços e aumentar o acesso é o Programa Farmácia Popular, lançado pelo governo federal em 2004, por meio de convênio com as prefeituras. As críticas ao programa têm sido feitas desde o início e a mais importante delas é que ele fere o princípio da universalidade do Sistema Único de Saúde, previsto na Constituição Federal. Ele retira recursos da distribuição gratuita e seria mais produto da propaganda do que política de saúde. Ele não está articulado ao Programa de Saúde da Família, o número de itens oferecidos, cerca de 100, é limitado e o número de farmácias está em torno de trezentos. Em março de 2006, o Governo Federal criou um "anexo" ao Programa Farmácia Popular, chamado Aqui tem Farmácia Popular. Cerca detrês mil farmácias comerciais credenciadas oferecem algumas dezenas de itens, basicamente, para tratar hipertensão ediabetes ${ }^{15}$. Prova da precariedade gerencial do programa: após um ano e meio de funcionamento, estão suspensos, por noventa dias, a partir de 10 de setembro último, o cadastramento das drogarias e farmácias. Prova da precariedade técnica do programa: hipertensão e diabetes estão entre as doenças mais prevalentes na população, as que mais matam e para as quais o tratamento farmacológico é necessário, seguro e consagrado. 
Deveria, portanto, ser alvo de políticas públicas consistentes e permanentes, com distribuição gratuita de remédios, monitoramento dos resultados e articulação com ações preventivas do Programa de Saúde da Família e com o Programa H iperdia do M inistério da Saúde. Entregar o controle dessas doenças aos mecanismos de mercado é andar na contramão do conhecimento epidemiológico consolidado sobre elas.

Assim, os remédios continuam caros e $90 \%$ dos brasileiros, cuja renda familiar não atinge três mil reais, têm acesso limitado.

$\mathrm{Na}$ outra ponta do consumo, os $10 \%$ da população que podem comprar remédios na farmácia comercial consomem em excesso. A transformação de situações corriqueiras em doença tem levado ao uso abusivo de medicamentos e à idéia falsa de que para tudo há uma pílula salvadora. Doenças são fabricadas. A timidez se transforma em distúrbio da ansiedade, os sintomas pré-menstruais em distúrbio disfórico, os problemas sexuais da mulher se transformam em disfunção sexual feminina ${ }^{16}$. Para todos eles, há um produto farmacêutico que vai, num passe de mágica, resolver o problema. Nesse processo, o marketing dosfabricantes torna seus cúmplices os profissionais de saúde e a população desinformada.

A prática do consumo simultâneo de muitos produtos leva a interações, sinergismos eao acúmulo de eventos adversos, nos quais os maiores prejudicados são os pacientes, principalmente os maisidosos. No Rio deJ aneiro, 1/3 deles usa cinco ou mais produtos ${ }^{17}$.

0 resultado da desigualdade de acesso: quem pode pagar acaba naufragando num mar de produtos muitas vezes inócuos, ou, com freqüência, nocivos. E, quem não pode, fica na fila da rede SUS esperando por medicamentos que não che gam, ou refém de iniciativas oficiais instáveis ede baixa cobertura.

\section{Algumas propostas}

Os críticos do modelo são postos sob suspeita de derrotistas e acusados de não oferecem propostas. M as propostas há. Vou apresentar algumas para 0 debate.

\section{No campo da assistência farmacêutica}

Propor, como se tem feito, que toda farmácia deva ter um farmacêutico presente durante todo o horário de funcionamento é o mínimo desejá- vel. A sua ação éespecialmente importantequando os regimes terapêuticos são complexos, com administração de múltiplos produtos, em pacientes idosos ou crônicos ${ }^{18}$.

Em vários países, já se reconhece o papel positivo do farmacêutico na melhoria da qualidade da prescrição e da dispensação e, por isso, foi possível avançar muito mais.

A Inglaterra é um deles. Lá, um estudo, do inicio da década de 1980, se tornou um marco na história da atividade farmacêutica. Foram comparados dois grupos de médicos; um deles recebeu visitais educativas defarmacêuticos clínicose material impresso, eo outro apenas material impresso. 0 objetivo da intervenção era melhorar a qualidade da prescrição, excluindo dela fármacos impróprios. Resultado: a proporção de médicos que passou a prescrever de acordo com as orientações científicas foi maior no grupo que recebeu as palestras dos farmacêuticos do que no grupo que recebeu apenas o material impresso ${ }^{19}$.

0 resultado de estudos como esse estimulou outros países a modificar o papel dos farmacêuticos e a melhorar a qualidade dos resultados dos tratamentos farmacológicos.

0 governo canadense vem defendendo $o$ incremento do papel dosfarmacêuticos como educadores e sua influência positiva no comportamento de quem prescreve ${ }^{20}$. Ainda no Canadá, conselhos regionais de farmácia fornecem boletins com informações atualizadas e testes autoaplicados, e condicionam a manutenção do registro profissional à aprovação em provas de conhecimento, a cada cinco anos.

Nos Estados Unidos, os farmacêuticos estão autorizados a fazer ajustes na farmacoterapia, de acordo com protocolos, em quarenta estados, executam imunização em 44 e têm autorização para prescrever e dispensar certas classes de fármacos que exigem receita, incluindo os anticoncepcionais emergenciais, em nove estado ${ }^{21}$.

$\mathrm{Na}$ Grã-Bretanha, há a prescrição suplementar, que é uma parceria entre um médico e um farmacêutico para, de comum acordo com o paciente, elaborar um plano de manejo clínico. Esse plano implica em o farmacêutico oferecer cuidados continuados a pacientes específicos, no uso de medicação cardiovascular, respiratória, endócrina, do sistema nervoso central e outras. Os profissionais são treinados em programas que incluem duzentas horas de estudo, trabaIham integrados com o clínico, podem solicitar exames laboratoriais e prescrever, segundo o plano previamente elaborado ${ }^{22}$. 
No campo da propaganda

A totalidade das peças publicitárias que veiculam propaganda de medicamentos viola, em algum item, a legislação brasileira atual. Segundo mostrou o pesquisador Álvaro Nascimento, elas superestimam a qualidade dos produtos anunciados e omitem seus aspectos negativos ${ }^{23}$. Uma importante forma de combater o uso desnecessário de medicamentos éo controle da propaganda. A proibição da publicidade de remédiosque exigem, ou não, receita médica, seria uma forma de desestimular o uso abusivo e melhorar a prescrição médica. Daí por que é importante que os profissionais de saúde, em geral, e os farmacêuticos, em particular, pressionem o poder legislativo para aprovar legislação que proíba a propaganda de medicamentos na mídia. Seria, sem dúvida, uma ação de cidadania.

\section{No campo da regulação}

Anos atrás, a Sociedade Internacional de Boletins sobre M edicamentos (International Society of Drug Bulletins), declarou o seguinte: A falta de transparência e de controle democrático das atividades regulatórias, e 0 fato de que as taxas pagas pel os fabricantes para obter autorização de funcionamento representarem mais de $50 \%$ do orçamento das agências regulatórias pode enfraquecer a consideração das necessi dades públicas e levar algumas agências a serem menos rigorosas vis-à-vis a indústria. É comum medir a efetivi dadedeuma agência em termos do número e da rapidez dos recursos provenientes das autorizações para a comercialização, ao invés da qualidade das decisões ${ }^{24}$.

No Brasil, a tão propalada autonomia gerencial, que serviu de sustentáculo para a argumentação dos que eram favoráveis à criação de uma agência reguladora externa à estrutura ministerial, vem sendo questionada, até por setores do governo, influenciados, talvez, pela crise no setor da aviação civil.

A criação da Anvisa, em 1999, retirou a regulação de medicamentos, no plano federal, da esfera direta do Estado. Passados esses anos, e diante das críticas, é importante que a atuação da agência seja avaliada globalmente, tendo em vista o modelo implantado. É preciso criar um grupo detrabalho independente, queinclua especialistas em segurança de medicamentos, para analisar os resultados concretos no enfrentamento das questões de saúde pública e na defesa do consumidor. A exigência deapresentar relatório anual das atividades, 0 instituto da ouvidoria - meca- nismos previstos no Projeto de Lei $n^{0} 3.337 / 2004$ - são importantes, porém insuficientes. A cobrança dessa avaliação global seria uma ação cidadã.

No campo do sistema de informação

É inconcebível que um país onde há perto de dozemilhões deinternações anuais no SU $\mathrm{S}^{25}$, com administração de pelo menos um medicamento, seja incapaz de saber quais produtos foram administrados para quais pacientes. É inimaginável que um sistema de informações como o SI H SUS, que detalha cada uma dessas internações, não possa, também, apresentar os registros dos medicamentos consumidos. Portanto, devemos exigir do M inistério da Saúde a alteração do sistema, para que possamos - médicos, farmacêuticos, pesquisadores - avaliar o impacto real uso dos produtos farmacêuticos no perfil epidemiológico dos pacientes internados.

\section{No campo dos valores}

É fundamental mudar as relações de leigos e de profissionais com a farmacoterapia, e modificar a cultura do "quanto mais melhor" no consumo de medicamentos. Eles são importantes demais para serem submetidosa relações de compra e de venda. Em vez de dar ouvidos à propaganda, é preciso consultar a literatura científica. Diante de sinais e sintomas de doença, deve-se pensar primeiro na possibilidade de instituir um tratamento não farmacológico. E, em caso de necessidade de tratamento farmacológico, sopesar riscos e benefícios. Osfarmacêuticos têm, sem dúvida, grande contribuição a dar nesse campo para o conjunto da sociedade.

\section{Conclusão}

Algumas pessoas poderiam pensar que pintei um quadro pessimista demais e que há inúmeros exemplos de ações bem-sucedidas na atual conjuntura. É verdade. M as é preciso lembrar que, exceto em situações de grandes catástrofes ou de guerras, é possível constatar a existência de meIhoras. M as, o fruto do trabal ho consciente e cidadão dos 400.000 profissionais farmacêuticose médicos do nosso país ${ }^{26,27}$ pode trazer resultados muito mais expressivos do que os que vêm sendo apresentados.

Continuo acreditando na capacidade de os governos oferecerem, com eqüidade, saúdee educação de boa qualidade; no papel dos organismos 
internacionais; e nas políticas de bem-estar social e de direitos civis. Acredito na organização das pessoas em torno a interesses legítimos, como forma ideal de fazer valer os direitos dos cidadãos.

Onde quer que o farmacêutico esteja, no hospital ou no centro de saúde, na rede pública ou em unidades particulares, na farmácia ou na indústria, na universidade ou nas unidades de farmacovigilância, eledeveter sempreem menteque os interesses sanitários da população devem prevalecer sobre os interesses econômicos de minorias.

É preciso combater, sem tréguas, a mercantilização da saúde e o pior fundamentalismo nos nossos tempos: o do consumo, inclusive de medicamentos.

É preciso ter a coragem afirmativa e dizer que outro mundo é possível. E que outro modelo de sociedadeénecessário.

\section{Agradecimentos}

A José Rubens Alcântara Bonfim, pelo envio dos textos da publicação The Annals of Pharmacotherapy utilizados nesse artigo. 


\section{Referências}

1. E-mail enviado por Zé Rodrix, publicado na coluna Gente Boa. 0 Globo 2007 Ago 29; p. 2.

2. Lince L. A farra dos bancos. Correio da Cidadania 2007 Ago 09. Disponível em: http://www. correioda cidadania.com.br

3. Angell M. The truth about drug companies - How they deceive us and what to do about it. New York: Random House; 2004.

4. M ortalidade infantil cai $46 \%$ no Brasil. Radio Agência [sítio na Internet]. [acessado 2007 Set 03]. Disponível em: http://www.radioagencianp.com.br/index php?option=com content\&task=view\&id=2879\&Itemid $=43$ font

5. Brasil. Em questão. [acessado 2007 Set 03]. Disponível em: http://www.brasil.gov.br/emquestao

6. M ão de obra infantil registra queda, mas 5,1 milhões ainda trabalham. 0 Globo 2007 Set 15; p. 38.

7. Saneamento muito longe da universalização. 0 Globo 2007 Set 15; p. 40

8. Campbell EG, Gruen RL, Mountford J, Miller LG Cleary PD, Blumenthal D. A national survey of physician-industry relationships. N Engl J Med 2007; 356:1742-1750.

9. Bodenheimer T. Uneasy alliance - clinical investigators and the pharmaceutical industry. N Engl J M ed 2000; 342(20):1539-1544.

10. Montori VM, Devereaux PJ, Adhikari NKJ, Burns KEA, Eggert CH, Briel MB, Lacchetti C, Leung TW Darling $E$, Bryant DM, Bucher $H C$, Schünemann $H J$, M eade M O, Cook DJ, Erwin PJ, Sood A, Sood R, Lo B, Thompson CA, Zhou O, Mills E, Guyatt GH Randomized trials stopped early for benefit a systematic review. JAM A 2005; 294:2203-2209.

11. Avorn J. Paying for drug approvals - who's using whom? N Engl J Med 2007; 356(17): 1697-1700.

12. Cawthorne P, Ford N, Limpananont J, Tienudom $\mathrm{N}$, Purahong W. WHO must defend patients' interests, not industry. The Lancet 2007; 369(9566): 974-975

13. Conselho Regional de Medicina do Estado de São Paulo. [acessado 2007 M ai 10] . Disponível em: http:/ /www.cremesp.org.br/library/modulos/publicacoes/ pdf/cartilha medicamentos.pdf
14. Visabrasil. [acessado 2007 Set 04]. Disponível em: www.visbrasil.org.br

15. Fiocruz. [acessado 2007 Set 11]. Disponível em: http:/ /www.fiocruz.br

16. Aronson JK. An agenda for research on adverse drug reactions. Br J Clin Pharmacol 2007; 64(2):119-121.

17. Rozenfeld S, Fonseca M JM, Acurcio FA. Drug utilization and polypharmacy among elderly, Rio de Janeiro State, Brazil: a survey. No prelo.

18. Hobson RJ, Seweell GJ. Supplementary prescribing by pharmacists in England. Am J H ealth-Sys Pharm 2006; 63:244-253.

19. Avorn J, Soumerai SB. Improving drug-therapy decisions through educational outreach. A randomized controlled trial of academically based "detailing". N Engl J Med 1983:308:1457-1463.

20. Greenhood KA, Patel P, Martin JE. What interventions should pharmacists employ to impact health practitioners' prescribing practices? Ann Pharmacother 2006; 40:1546-1557.

21. Karpa KD. Pharmacist critique was ill-informed. Ann Pharmacother 2006;40:1441-1444.

22. Johnson G, MCCaig DJ, Bond CM, Cunningham S, Diack HL, Watson AM, Stewart DC. Supplementary prescribing: early experiences of pharmacists in Great Britain. Ann Pharmacother 2006; 40:1843-1850.

23. Nascimento $A$. "Ao persistirem os sintomas, o médico deverá ser consultado". Isto é regulação? São Paulo: Sobravime; 2005.

24. International Society of Drug Bulletins. [acessado 2004 Jan]. Disponível em: http://www.isdbweb. dspace.it/pag/

25. DATASUS. [acessado 2007 Set 19]. Disponível em: http://www.datasus.gov.br

26. Associação M édica Brasileira. [acessado 2007 Set 19]. Disponível em: http://www.amb.org.br/mc noticias1 abre.php3?w id $=1829$

27. Conselho Federal de Farmácia. [acessado 2007 Set 19]. Disponível em: http://www.cff.org.br:80/cff/ mostraPagina. asp?codServico $=67 \& \operatorname{codPagina}=287$ 